\title{
Effect of residue management practices on yield and economic viability of Malaysian pineapple production
}

\begin{abstract}
This paper communicates the effect of in situ burning of pineapple residues (IBPR), in situ decomposition of pineapple residues untouched (IDPR), and the application of the zero burn technique (ZBT, i.e., slashing, raking and stacking of leaves, crowns, and peduncles from $2 \mathrm{~m}$ (wide) beds into $3 \mathrm{~m}$ (wide) beds, respectively, on yield. It also compares the economic viability of these residue management practices. The Net Present Value (NPV) was used to compare the economic viability of the three residue management practices. The three residue management practices did not significantly improve yield. Taking into account the cost of environmental pollution associated with burning of pineapple residues, the NPV analysis revealed that either the IDPR or the ZBT practices can serve as an economically competitive alternative to the usual method of burning pineapple residues. (c) 2002 by The Haworth Press, Inc. All rights reserved.
\end{abstract}

Keyword: Economic viability; Fruit yield; Malaysia; Peat; Pineapple residues 